\title{
Influência meteorológica no leucograma e na população citológica do trato respiratório de bezerros ${ }^{1}$
}

\author{
Heloisa G. Bertagnon ${ }^{2 *}$, Greyson V.Z. Esper², Mauren P. Emanuelli² \\ e Luis Giovani de Pellegrine ${ }^{2}$
}

\begin{abstract}
Bertagnon H.G., Esper G.V.Z., Emanuelli M.P. \& Pellegrine L.G. 2011. [Meteorologic influence on leucogram and cytology in the respiratory tract of healthy calves.] Influência meteorológica no leucograma e na população citológica do trato respiratório de bezerros. Pesquisa Veterinária Brasileira 31(3):244-246. Faculdade de Veterinária, Universidade Estadual do Centro Oeste, Rua Simeão Camargo Varella de Sá 3, Guarapuava, PR 85040-080, Brazil. E-mail: hgodoi@usp.br

The study sought to evaluate whether environment temperature $(T)$ and relative humidity (UR) had an impact on the leucogram and cytology of the respiratory tract of healthy cattle. Blood and tracheobronchial lavage were collected from 5 female healthy 4 to 7 month-old Jersey calves in three moments: $\mathrm{T} 1\left(\mathrm{~T}=5^{\circ} \mathrm{C}, \mathrm{UR}=93 \%\right) \mathrm{T} 2$ (control environment temperature, $\left.\mathrm{T} 22^{\circ} \mathrm{C}, \mathrm{UR} 80 \%\right)$, and $\mathrm{T} 3\left(\mathrm{~T}=30^{\circ} \mathrm{C}, \mathrm{UR}=41 \%\right)$. Monocytosis in the leucogram and a decrease in alveolar giant macrophages were observed in T3. It appears that the weather condition had an influence on the respiratory immune system of the calves due to a stress situation. We conclude that elevated temperature associated with low relative humidity appears to favor respiratory disease in 4 to 7 -month-old calves.
\end{abstract}

INDEX TERMS: Respiratory tract, environment temperature, cattle.

RESUMO.- Com o intuito de verificar a influência de diferentes condições meteorológicas na sanidade de bovinos, foi realizado citologia de lavados traqueobrônquicos obtidos por traqueocentese e leucograma sanguíneo de cinco bezerros em situações de extremos de temperatura ambiental, sendo $\mathrm{T} 1=\mathrm{T}$ (temperatura ambiental) de $5^{\circ} \mathrm{C}$ e UR (umidade relativa do ar) $93 \%$; T2 = temperatura controle de $\mathrm{T} 22^{\circ} \mathrm{C}$ e UR $80 \%$; e T3 $=$ T $30^{\circ} \mathrm{C}$ e UR $41 \%$. Pode-se observar que a condição T3 provavelmente gerou estresse nos animais, pois se observou monocitose significativa no leucograma e na análise do lavado traqueobrônquico, uma diminuição significativa de macrófagos alveolares gigantes, provavelmente por diminuição da atividade macrofágica alveolar, caracterizando esta temperatura e umidade relativa do ar como favoráveis ao aparecimento de doenças respiratórias.

TERMOS DE INDEXAÇÃO: Aparelho respiratório, temperatura ambiental, bovinos.

\footnotetext{
1 Recebido em 25 de setembro de 2010.

Aceito para publicação em 19 de outubro de 2010.

${ }^{2}$ Faculdade de Veterinária, Universidade Estadual do Centro Oeste, (Unicentro), Campus Cedeteg, Rua Simeão Camargo Varela de Sá 3, Vila Carli, Guarapuava, PR 85040-080, Brasil. *Autor para correspondência: hgodoi@usp.br
}

\section{INTRODUÇÃO}

Diariamente os bovinos são expostos a diversos fatores agressores, e mesmo assim a maioria deles se mantém saudáveis devido a eficientes mecanismos de defesa física, celular e humoral (Liggitt 1985). No entanto situações como extremos de temperatura, transporte, união de animais de várias origens são causas comuns de estresse em bovinos que podem provocar alterações fisiológicas e hematológicas diminuindo a efetividade da resposta imunológica (Jain 1993, Muller et al. 1994, Paes et al. 2000).

O principal hormônio associado a condição estressante é o cortisol, que dependendo de seus teores séricos pode causar o leucograma caracterizado por neutrofilia, linfopenia, acompanhada ou não por alterações nos valores de monócitos, eosinófilos e contagem total de leucócitos, com redução da fagocitose e das funções oxidativas dos neutrófilos (Jain 1993, Raidal et al. 1997). Além de influenciar na imunidade sanguínea, o cortisol também interfere na citologia do trato respiratório, diminuindo a ativação e poder de fagocitose de macrófagos alveolares e o metabolismo oxidativo de neutrófilos do lavado respiratório (Crisman et al. 1992, Raidal et al. 1997, Ishizaki et al. 2005). Por isso, eventos estressantes podem desencadear doenças respiratórias como pneumonia causando grandes prejuí- 
zos na pecuária brasileira e mundial. Estas enfermidades podem ser evidenciadas através de exame físico minucioso, aliado a alguns exames complementares como hemograma,(Paes et al. 2000, Feitosa 2004) e análise microbiológica e citológica da região traqueobrônquica e/ou broncoalveolar, amplamente pesquisada em bovinos e eqüinos. (Liggitt 1985, Jain 1993, Feitosa 2004, Ishizaki et al. 2005, Bohn \& Calla 2007).

Devido a grande variação de temperatura ambiental em Guarapuava, o presente trabalho verificou a influência metereológica nos parâmetros sanguíneos e na citologia da região traqueobrônquica de bovinos de 4 a 7 meses de idade criados a pasto.

\section{MATERIAL E MÉTODOS}

Foram selecionadas cinco bezerras, com 4-7 meses de idade, da raça Jersey, hígidas, oriundas da Unidade Didática de Bovinos de Leite da Universidade Estadual Centro Oeste (Unicentro), em Guarapuava-PR, criados a pasto sem abrigo de vento ou chuva lotados no mesmo piquete durante todo o período experimental.

Os animais foram submetidas a colheita de sangue e lavado traqueobrônquico em três diferentes condições meteorológicas, sendo $\mathrm{T} 1=$ temperatura $(\mathrm{T})$ de $5^{\circ} \mathrm{C}$ e umidade relativa do ar (UR) de 93\%, T2 = condição ambiental controle com T de $22^{\circ} \mathrm{C}$ e UR de $80 \%$, e T3 $=$ T de $30^{\circ} \mathrm{C}$ e UR de $41 \%$, respeitando-se um intervalo mínimo entre as colheitas de sete dias.

A avaliação das bezerras foi feita por exame clínico preconizado por Feitosa (2004), com a finalidade de garantir a higidez dos mesmos, e exames laboratoriais compostos por hemograma e citologia traqueobrônquica. A coleta da amostra de sangue foi realizada por punção da veia jugular externa, em tubo contendo o anticoagulante EDTA, para realização do hemograma conforme a técnica descrita por Jain (1993) o lavado traqueobrônquico foi colhido através da técnica de traqueocentese, realizada no terço médio da traquéia por punção com agulha hipodérmica $50 \times 16$, através da qual passou-se um cateter de polietileno de $30,4 \mathrm{~cm}$ de comprimento, introduzido até a região da bifurcação traqueal. Pelo cateter administrou-se três alíquotas de $20 \mathrm{ml}$ de solução fisiológica isotônica estéril, sendo o conteúdo recuperado pela aspiração com uma seringa plástica de 60 $\mathrm{ml}$. Posteriormente o lavado obtido foi centrifugado o sobrenadante desprezado, e a partir do precipitado, confeccionado um esfregaço corado pelo corante Panótico rápido. A leitura das lâminas foram realizadas por uma única pessoa em microscópio de luz com um aumento de 1000, sendo classificadas 400 células de acordo com suas características morfológicas e tintoriais.

A análise estatística utilizada foi análise de variância. $O$ teste utilizado foi o PRO GLM para análise das variâncias das médias e teste de Tukey a 5\% para comparação das médias. Os dados foram analisados pelo pacote estatístico SAS (1993).

\section{RESULTADOS E DISCUSSÃO}

Os valores referentes ao leucograma dos animais estão apresentados no Quadro 1. Todos os parâmetros do hemograma estavam dentro dos valores de referências para bovinos hígidos da raça Jersey (Birgel Junior et al. 2001). No geral não houve diferença entre os grupos para a maioria das variáveis, apenas para os monócitos, que se elevaram a medida que a temperatura ambiental aumentou e a umidade relativa do ar diminuiu. Estes achados corroboram com as conclusões de Birgel Junior et al. (2001) onde se espera diferença no resultado de leucograma quando os bovinos são submetidos a diferentes condições ambientais. Provavelmente esta condição meteorológica pode ter provocado uma resposta de estresse, liberando cortisol em quantidades suficientes para causar apenas monocitose sem alterar as demais variáveis do hemograma (Jain 1993, Smith 2004). De acordo com McManus et al. (2009) alterações de temperatura e umidade relativa do ar podem promover alterações distintas nas contagens dos diferentes tipos leucocitários de acordo com a capacidade de adaptação de cada raça bovina, mostrando uma boa adaptabilidade desta raça em questão ao frio, mas não ao calor.

Os valores referentes a citologia da região traqueobrônquica estão presentes no Quadro 2, e são semelhantes aos encontrados por Bohn \& Callan (2007) porém diferente dos achados por Liggitt (1985) e Wachholz et al. (2004). Diferenças de manejo, idade, raça e técnica utilizada para coIheita poderiam resultar nestas diferenças (Pringle et al. 1988, Gonçalves 1997), por isso minimizou-se estas variáveis quando estudou-se os achados citológicos dos mesmos animais, criados nas mesmas condições de manejo, com faixa etária fixa (4-7 meses de idade), submetidos a mesma técnica de colheita e sem evidencia clínica de doença respiratória durante todo o período experimental, podendo-se pressupor que as diferenças encontradas foram relacionadas às diferentes condições meteorológicas.

\begin{tabular}{lccc}
$\begin{array}{c}\text { Quadro 1. Valores das médias e desvios padrões da contagem absoluta } \\
\text { de leucograma de bovinos submetidos a diferentes condições } \\
\text { meteorológicas, Guarapuava, PR, 2010 } \\
\text { Leucograma }\end{array}$ & \multicolumn{3}{c}{ Condições meteorológicas } \\
\cline { 2 - 4 } T1 a & T2 & T3 \\
\hline Leucócitos & $9780(813,27)^{\mathrm{A}}$ & $8620(636,71)^{\mathrm{A}}$ & $10470(1783,37)^{\mathrm{A}}$ \\
N Bastonetes & $23,8(23,80)^{\mathrm{A}}$ & $87,4(30,12)^{\mathrm{A}}$ & $46,2(29,17)^{\mathrm{A}}$ \\
N Segmentados & $2358,8(356,42)^{\mathrm{A}}$ & $1527,2(196,43)^{\mathrm{A}}$ & $1748,3(426,12)^{\mathrm{A}}$ \\
Linfócitos & $7058,4(621,16)^{\mathrm{A}}$ & $6667,2(428,43)^{\mathrm{A}}$ & $8173,8(1556,01)^{\mathrm{A}}$ \\
Monócitos & $50,0(3147)^{\mathrm{A}}$ & $93,0(42,38)^{\mathrm{A}}$ & $210,7(26,14)^{\mathrm{B}}$ \\
Eosinófilos & $251,6(175,14)^{\mathrm{A}}$ & $213(148,76)^{\mathrm{A}}$ & $222,1(160,94)^{\mathrm{A}}$ \\
Basófilos & $37,4(23,06)^{\mathrm{A}}$ & $32,2(20,56)^{\mathrm{A}}$ & $51,7(34,48)^{\mathrm{A}}$
\end{tabular}

Diferentes letras na mesma linha indicam que houve diferença estatística $p<0,05$. a T1: T $5^{\circ} \mathrm{C}$, UR $93 \%$; T2: T $22^{\circ} \mathrm{C}$, UR $80 \%$; T3: T $30^{\circ} \mathrm{C}$, UR $41 \%$. 
Quadro 2. Valores das médias e desvios padrões da contagem diferencial citológica da região traqueobrônquica de bovinos submetidos a condições meteorológicas, Guarapuava, PR, 2010

\begin{tabular}{lccc}
\hline \multirow{2}{*}{ Citologia } & \multicolumn{3}{c}{ Condições meteorológicas } \\
\cline { 2 - 4 } & $\mathrm{T}^{\mathrm{a}}$ & $\mathrm{T} 2$ & $\mathrm{~T} 3$ \\
\hline Macrófago & $44,4(12)^{\mathrm{A}}$ & $43,3(8,4)^{\mathrm{A}}$ & $52,34(7,5)^{\mathrm{A}}$ \\
Macrófago gigante & $3,2(2)^{\mathrm{A}}$ & $4,5(2,2)^{\mathrm{A}}$ & $0,9(1,4)^{\mathrm{B}}$ \\
Linfócitos & $5,8(4,2)^{\mathrm{A}}$ & $7,1(4,6)^{\mathrm{A}}$ & $3,4(1,9)^{\mathrm{A}}$ \\
$\mathrm{N}$ segmentados & $23,7(12,9)^{\mathrm{A}}$ & $8,05(2,4)^{\mathrm{A}}$ & $17,9(11,8)^{\mathrm{A}}$ \\
Eosinófilos & $0,0(0)^{\mathrm{A}}$ & $1,1(1)^{\mathrm{A}}$ & $0,4(0,5)^{\mathrm{A}}$ \\
Células & $22,6(7,9)^{\mathrm{A}}$ & $35,8(14,9)^{\mathrm{A}}$ & $25,3(10,5)^{\mathrm{A}}$ \\
traqueobrônquicas & & &
\end{tabular}

Diferentes letras na mesma linha indicam que houve diferença estatística $\mathrm{p}<0,05$.

a T1: T 5ㄷ, UR 93\%; T2: T $22^{\circ} \mathrm{C}$, UR $80 \%$; T3: T $30^{\circ} \mathrm{C}$, UR $41 \%$

Não houve diferenças significativas entre a maioria das células em função das diferentes condições ambientais, apenas os macrófagos gigantes da condição T3 que apresentaram uma redução significante em comparação a condição ambiental controle (T2), Yamamoto \& Sato (2002) observaram diminuição de macrófagos alveolares quando submeteram ratos a temperaturas de $35^{\circ} \mathrm{C}$ provavelmente por uma menor passagem de monócitos do sangue para o pulmão. Durante a resposta imunológica normal, agentes estranhos induzem a união de dois ou mais macrófagos formando células sinciciais multinucleadas com um tamanho maior e conseqüentemente apresentam uma melhor capacidade de fagocitose. Como o estresse pode levar a uma diminuição da atividade macrofágica em bovinos e eqüinos (Pringle et al 1988, Ishizaki 2005, Bohn \& Calla 2007), pode-se cogitar que houve uma menor atividade macrofágica, diminuindo portanto a formação destas células multinucleadas, o que deixaria as bezerras mais susceptíveis a infecções respiratórias em situações de altas temperaturas e baixa umidade relativa do ar. As pesquisas que avaliaram a influência do estresse na população celular respiratória não diferenciaram macrófago normal de macrófago gigante, mas encontraram menor poder de ativação e de fagocitose macrofágica, em situações estressantes (Pringle et al. 1988, Ishizaki et al. 2005, Bohn \& Calla 2007).

A condição T1 não interferiu no hemograma nem na citologia em comparação a condição meteorológica controle (T2) provavelmente porque os bezerros estavam adaptados a estas condições meteorológicas, não sofrendo situação de estresse.

\section{CONCLUSÃO}

Altas temperaturas ambientais relacionadas à baixa umidade relativa do ar é uma condição ambiental que influen- cia o hemograma e a citologia do trato respiratório de bezerros criados a pasto, aumentando a susceptibilidade destes animais a doenças respiratórias.

\section{REFERÊNCIAS}

Birgel Júnior E.H., D’angelo J.L., Benesi F.J. \& Birgel E.H. 2001. Valores de referências do leucograma de bovinos da raça Jersey criados no Estado de São Paulo. Braz. J. Vet. Res. Anim. Sci. 38:136141.

Bohn A.A. \& Calla R.J. 2007. Cytology in food animal practice. Vet. Clin. North Am., Food. Anim. Pract. 23:443-479.

Crisman M.V., Hodgson D.R., Bayly W.M. \& Liggitt H.D. 1992. Effects of transport on constituents of bronchoalveolar lavage fluid from horse. Cornell. Vet. 82:233-246

Feitosa F.L. 2004. Semiologia: a arte do diagnóstico. Roca, São Paulo. 807p.

Gonçalves R.C.1997. Estudo clínico e citológico em bezerros clinicamente sadios e portadores de broncopneumonia moderada e grave. Tese de Doutorado em Patologia, Faculdade de Ciências Agrárias e Veterinárias, Universidade Estadual Paulista, Botucatu, SP. 144p.

Ishizaki H., Hanafusa Y. \& Kariya Y. 2005. Influence of truck transportation on the function of bronchoalveolar lavage fluid cells in cattle. Vet. Immunol. Immunopathol. 105:67-74.

Jain N.C. 1993. Essentials of Veterinary Hematology. Lea and Febiger, Philadelphia. 417p.

Liggitt H.D. 1985. Defense mechanism in the bovine lung. Vet. Clin. North Am., Food. Anim. Pract. 1:347-366.

McManus C., Prescott E., Paludo G.R., Bianchini E., Louvandini H. \& Mariante A.S. 2009. Heat tolerance in naturalized Brazilian cattle breeds. Livest. Sci. 120:256-264.

Muller C.J.C., Botha J.A. \& Smith W.A. 1994. Effect of shade on various parameters of Friesian cows in a Mediterranean climate in South Africa. Behavior South Afr. J. Anim. Sci. 24:61-66.

Paes P.R., Barioni G. \& Fonteque J.R. 2000. Comparação de valores hematológicos entre caprinos fêmeas da raça parda alpina de diferentes faixas etárias. Vet. Notícias 6:43-49.

Pringle J.K., Viel L., Shewen P.E., Willoughby R.A., Martin S.W. \& Valli V.E. 1988. Bronchoalveolar lavage of cranial and caudal lung regions in selected normal calves: Cellular, microbiological, immunoglobulin, serological and histopathological variables. Can. J. Vet. Res. 52:239248.

Raidal S.L., Baily G.D. \& Love D.N. 1997. Effect of transportation on lower respiratory tract contamination and peripheral blood neutrophil function. Aust. Vet. J. 75:433-438.

SAS Institute 1993. Sas/Stat User's Guide: Statistics, Version 6. Vol.2. $4^{\text {th }}$ ed. North Caroline. 943p.

Smith B.P. 2005. Large Animal Internal Medicine. $3^{\text {rd }}$ ed. Manole, São Paulo. 1784p.

Yamamoto S. \& Sato K. 2002.The effect of the high temperature in alveolar macrophage count in bronchoalveolar lavage fluid of F344 rats. Exp. Anim. 51:505-508

Wachholz L., Bertagnon H.G., Mori E., Fernandez W.R. \& Benesi F. 2004. Cytology of tracheobronchial and bronchoalveolar lavages em Holstein calves without respiratory distress on first month of live. Annals $23^{\text {rd }}$ World Buiatrics Congress, Quebec, Canada, p.25. (Abstract) 